\title{
The Hippocratic Method for the Reduction of the Mandibular Dislocation, an Ancient Greek Procedure Still in Use in Maxillofacial Surgery
}

\author{
Vasilios Thomaidis, Gregory Tsoucalas, Aliki Fiska
}

\author{
Department of Anatomy, Medical School \\ Democritus University of Thrace, \\ Alexandroupolis, Greece \\ Correspondence: \\ gregorytsoucalas@yahoo.gr \\ Tel: + 302421078583 \\ Fax.: + 302421078160
}

Received: 2 February 2018

Accepted: 13 April 2018

Key words: Mandibular dislocation Temporomandibular joint dislocation - Reduction - Maxillofacial surgery • Hippocrates.

\begin{abstract}
Mandibular dislocation remains an acute medical condition in maxillofacial surgery. Since the Hippocratic era its reduction has been performed exactly in the same way it is now performed in modern surgery. We report an example of an elderly female patient with bilateral mandibular dislocation, who came to our department and was treated under sedation using the Hippocratic bimanual intraoral technique by two medical personnel, depicting the timeless usage of the method. Although some characteristics of the procedure were wrongfully attributed to others, such as Barton and Lewis, after a thorough examination of the ancient Greek medical texts, its originality should in fact be attributed solely to the Hippocratic School of Medicine. Furthermore, we recommend the use of the term "mandibular dislocation" instead of the "temporomandibular joint dislocation", as a more accurate medical definition.
\end{abstract}

\section{Introduction}

Although opinions concerning knowledge of anatomy in the Hippocratic era are controversial, Hippocrates and his followers were the first to introduce clinical anatomy. Even though post mortem examination was strictly prohibited, both by law and religious ethics, the Hippocratic school of medicophilosophers acquired sufficient experience to understand the human body's skeletal system, and described a series of bone fractures and dislocations. Apart from simply noting bone and joint disfigurations, they proposed treatment and palliation methods. their anatomic knowledge is revealed in "Corpus Hippocraticum" and especially in the treatises "Mox入ıкó $\varsigma$ " (On the Instru-

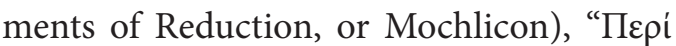

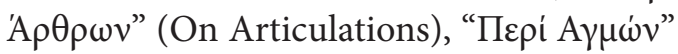

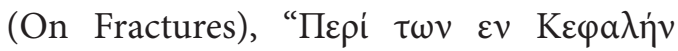

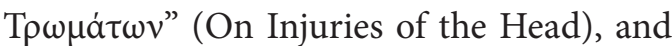

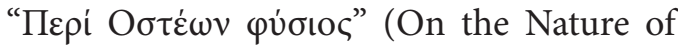
the Bones) (Figure 1) (1). Among the plethora of orthopaedic interventional treatment procedures introduced by the Hippocratic School, stands the method for reduction of mandibular dislocation (MD) (2).

$\mathrm{MD}$ is nowadays an uncommon pathology, constituting a pathophysiological joint condition presenting oral and maxillofacial surgeons with a challenge in its management (3). The condyle of the mandible articulates bilaterally in a concavity, known as the glenoid fossa, or simply the mandibular fossa. Its dislocation, when the condylar process 


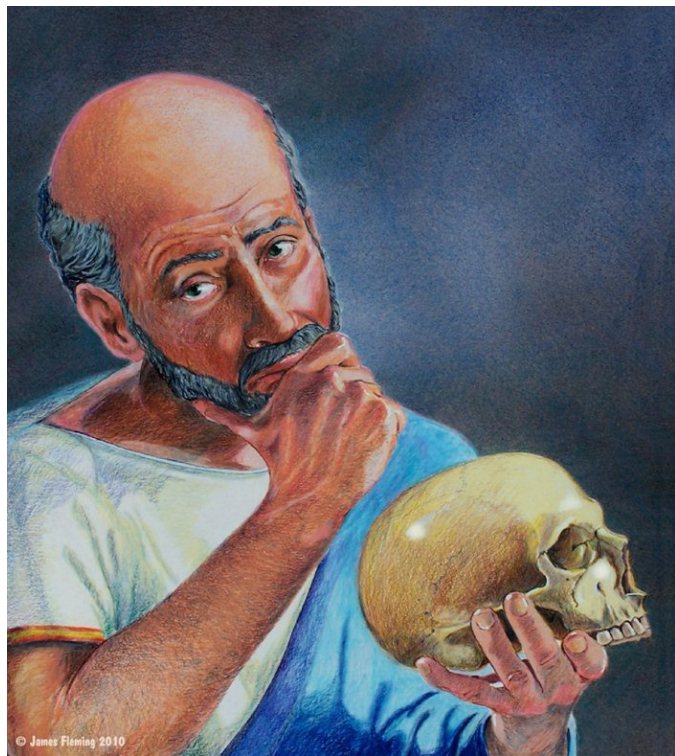

Figure 1. Hippocrates studding the anatomy of a human skull, aquarelle by James Fleming, 2010.

is displaced out of the glenoid fossa, is due to either imbalance in the neuromuscular function, or structural deficit. Conservative interventional methods in its management include symptomatic pain relief with analgesics, and manual reduction (4). This simple approach was in fact introduced about 2500 years ago by Hippocrates and his pupils (2).

We report, as an example, an 80 year old female patient with a missed case of bilateral MD, treated conservatively with the use of the Hippocratic method. Our case may present nothing new, but it links some misunderstood facts and contributors with the truth of the ancient Greek Corpus Hippocraticum. We furthermore propose the term "mandibular dislocation" for such a condition, as a more accurate medical definition in term of clinical anatomy.

\section{A modern case report}

The patient was admitted to our private department presenting with an open bite, an anxious face and mild drooling of saliva. Physical examination, after palpation of the

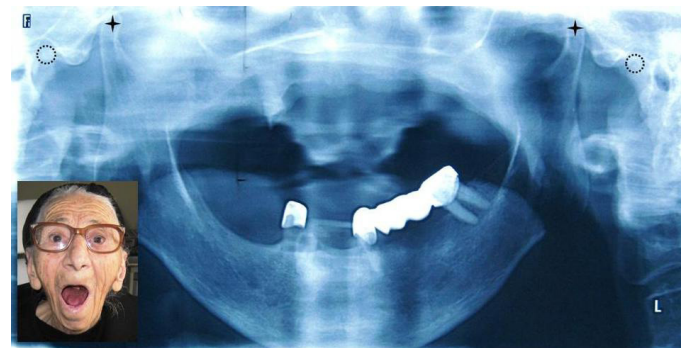

Figure 2. Clinical appearance of a bilateral dislocation of the mandible, an 80 year old female patient and $x$-ray depicting the bilateral dislocation of the mandible (circles=the articular positions, stars=the dislocated condyles).

preauricular region, revealed emptiness in the joint space. The patient remembered a "strange feeling of movement in her mandible after yawning" 6 months prior to her visit. Her scoring with the validation scale tool "Greek Brief Pain Inventory" (GBPI) was $3(0=$ no pain, $10=$ severe pain, plus optical scale), reporting almost no pain at all. Her nutrition included mostly ground food and soups because her oral cavity presented an almost complete absence of teeth. Furthermore, she had refused to use dentures. Supplementary pathology included osteoporosis, diffused athropathia, mild anaemia, and vascular dementia (MMSE=17). X-ray revealed a bilateral MD of Type III by Akinbami's classification (the head of the condyle is high-up in front of the base of the eminence) (Figure 2) (4-5). Manual reduction of the MD under general anaesthesia and muscular relaxants was selected to avoid a possibly severe and painful incident. There were no immediate complications and the patient was discharged with the suggestion of follow-up by a maxillofacial surgeon.

\section{Discussion}

In Corpus Hippocraticum (cca 5th-4th century BC), in the treatise "Mochlicon" there is a very accurate description of MD, attributed to tendon relaxation and muscle atrophy, 


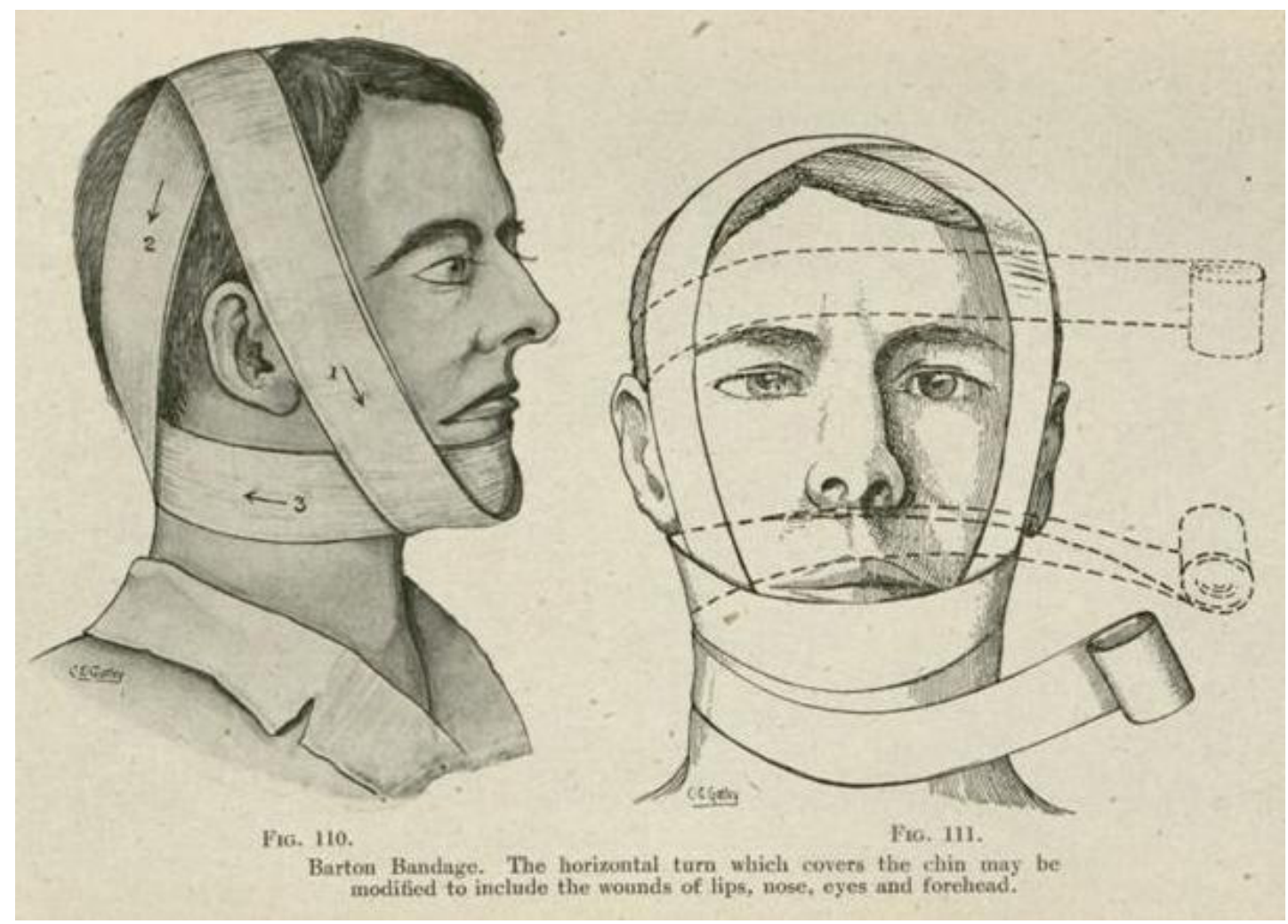

Figure 3. Gorley CE. The Barton Bandage, Centre for the History of Medicine: https:/collections.countway.harvard.edu/onview/items/show/17962.

classified as unilateral and bilateral, mainly caused by yawning. It was described as a rare condition, which needed to be quickly addressed, while the bilateral form was noted as more harmful. The treatment was also thoroughly described: "The patient is put in a lying or sitting position, while an assistant must hold the head tightly in a steady position. The physician grabs the mandible with his two arms from inside and outside the oral cavity (today: the external oblique line and the area under the mandible), from both sides, left and right, performing 3 manipulations simultaneously. He lifts up the mandible, pushes it backwards while closing the oral cavity, all at once. Painkillers should be given (today opioids). The mandible should be fixed in its normal position with the aid of bandages (today: Barton bandage)" (2). This method is still in use. Although Hippocrates was the one who introduced the practice of bandages for the mandible to be fixed, the international nomenclature attributed it to naval surgeon, William Paul Crillon Barton (1786-1856) (Figure 3).

Furthermore, researchers believe that Lewis modified the procedure in 1981 by proposing the sitting position (4-6), while this had already been suggested in the Hippocratic era (Greek fragment: $\kappa a \theta \eta \mu \varepsilon \dot{v o v}$

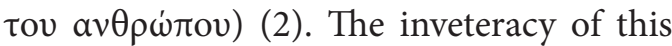
method may be further certified by both the reference and the illustration in the manual of Appolonius of Citium in Cyprus (c. 1st century BC) (Figure 4) (7).

Apart from the Hippocratic understanding of the role of the weakening of the local musculature, the "open lock sign" was also known (Greek fragment: $\pi \rho \circ \dot{\varepsilon} \chi \varepsilon \iota \eta$

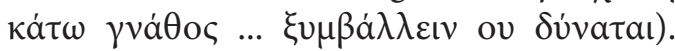
The original ancient text describes what surgeons nowadays express as "the mandible 


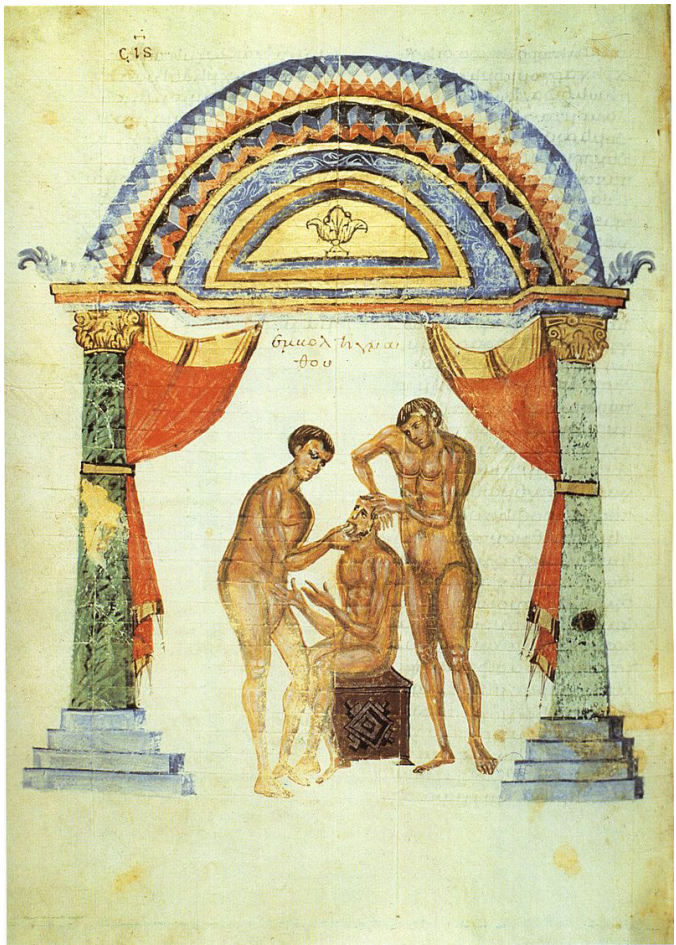

Figure 4. Apollonios von Kition. De articulis. Buchmalerei nach dem Vorbild einer Zeichnung in einer antiken Handschrift Einrenkung des Unterkiefers. Florenz Biblioteca Medicea Laurenziana Plut 747 fol 198v. (Book illustration from the example of a drawing in an ancient manuscript of reduction of the lower jaw).

is postured forwards...an open bite". Furthermore, medico-philosophers of the Hippocratic era, faithful to the ancient Greek tradition of accurate anatomic orientation, described exactly the MD as "the mandible leaving its place". Thus, a bone is moved from its normal articular position, not the joint itself (2). Having in mind that a joint cannot be moved, we may note that the expression used by a plethora of modern researchers "temporomandibular joint dislocation" (3$5,8)$ is in fact an incorrect anatomic term which should be abandoned.

Our patient reported no pain, while an acute dislocation is usually a very painful clinical entity (4). Her age and nutrition (muscular atrophy), combined with vascular dementia may explain her condition. Fur- thermore, her low cognitive reserve, her rural residency, the complete absence of teeth and dementia all contributed to a neglected and/or non-perceptible incidence. In the end, she was treated with a method dating back to Greek antiquity, which is about 2500 years old. The bilateral MD dislocation was easily reduced using the Hippocratic bimanual intraoral technique under sedation, with two medical personnel present $(2,9)$. Pain, during and after the procedure, in our case was dealt with the administration of opioids (codeine and tramadol). In the Hippocratic era, herbal drugs based on meconium (Greek: $\mu \eta \kappa \omega \dot{v} \iota \mathrm{v})$, most probably the Papaver Somniferum plant, were considered as narcotics and painkillers (10). Moreover, Thessaly's endemic plant, mandrake (known also as mandragoras, Greek: $\mu \alpha v \delta \rho \alpha \gamma$ ópac) was also widely administered as a sedative and narcotic drug during surgical procedures (11). Personalized confrontation of the pain with opioids, represents one more similarity to be added to the apposition of ancient Greek and modern maxillofacial surgery.

Although various interventional Hippocratic techniques remain timeless, the management of facial trauma in the Hippocratic era is underestimated and usually neglected when historians trace the origin of modern methodology. Techniques from the past were named after modern physicians who were considered to be the innovators, whilst the true pioneers remain unappreciated. The advancement of medicine has only further established the Hippocratic dogma for the reduction of MD (12).

\section{Epilogue}

The Hippocratic School of Medicine, through thorough observation and extended acquired experience, succeeded in establishing surgical techniques which have endured time. The Hippocratic intervention 
for reduction of a MD is a simple non-surgical procedure still used by modern maxillofacial surgeons. Due to its global acceptance, one may even say that it is a medical dogma, a timeless manoeuvre which, in most situations, is the right conventional intervention to be used in MD.

Authors' contributions: Conception and design: VT and GT; Acquisition, analysis and interpretation of data: VT; Drafting the article: GT; Revising it critically for important intellectual content: VT and AF; Approved final version of the manuscript: AF.

Conflict of interest: The author declares that he has no conflict of interest.

\section{References}

1. Samothrakes Ath. The Anatomical knowledge of Hippocrates [in Greek] Greek Medicine. 1939;13: 732-45.

2. Hippocrates. Mochlique [in French]. In: Littré E, editor. Hippocratic Collection [in French]. Vol. 6. Paris: Littré-Baillière; 1844.

3. Liddel A, Perez DE. Temporomandibular Joint Dislocation. Oral Maxillofacial Surg Clin North Am. 2015;27(1):125-36.

4. Sharma NK, Singh AK, Pandey A, Verma V, Singh S. Temporomandibular joint dislocation. Natl J Maxillofac Surg. 2015;6(1):16-20.
5. Akinbami B. Evaluation of the mechanism and principles of management of temporomandibular joint dislocation. Systematic review of literature and a proposed new classification of temporomandibular joint dislocation. Head Face Med. 2011;7:10.

6. Lewis JE. A simple technique for reduction of long-standing dislocation of the mandible. $\mathrm{Br} \mathrm{J}$ Oral Surg. 1981;19(1):52-6.

7. Apollonii Citiensis. Scholia on Hippocratem and Galenum. Regimontii Pressorum; 1834.

8. Yoshida H, Nakatani YI, Gamoh S, Shimizutani K, Morita S. Clinical outcome after 36 months of treatment with injections of autologous blood for recurrent dislocation of the temporomandibular joint. Br J Oral Maxillofac Surg. 2018;56(1):64-6.

9. Oliphant R, Key B, Dawson C, Chung D. Bilateral temporomandibular joint dislocation following pulmonary function testing: a case report and review of closed reduction techniques. Emerg Med J. 2008;25(7):435-6.

10. Hippocrates. Epidemics II [in French]. In: Littré E, editor. Hippocratic Collection [in French]. Vol. 5. Paris: Littré-Baillière; 1846.

11. Tsoucalas G, Sgantzos M, Androutsos G. Hippocrates, Principles on Abdominal Surgery in Ancient Greece During the Fifth Century bc. Surg Innov. 2016;23(2):212-3.

12. Gahhos F, Ariyan S. Facial fractures: Hippocratic management. Head Neck Surg. 1984;6(6):100713. 